\title{
HUBUNGAN PROFESIONALISME GURU DENGAN PRESTASI BELAJAR AL-QUR'AN HADITS SISWA DI MADRASAH TSANAWIYAH GUPPI SUMBEREJO TANGGAMUS
}

\author{
Mahmudah, Muhtarom, Evi Gusliana \\ J1. Raya Wonokriyo Gadingrejo Pringsewu \\ Email: stitpringsewu@gmail.com
}

\begin{abstract}
Abstrac
The development of education is increasingly in need of management system that good.For the development of education in need of people who was really experts in their fields. Profession is essentially a job that requires knowledge and skills that are highly qualified to serve or serves the public interest to achieve human well-being, especially in the field of education. This research generally aims to collect information on efforts to improve teacher profesionalisme of Qur'an hadith lesson in MTs GUPPI district Sumberejo Kab.Tanggamus.

This study was conducted on 38 students MTs GUPPI Sumberejo (34\%) as a sample of the student population as much as 117 which consists of class VII, VIII, and IX class and subject teachers of the Qur'an and hadith. Data were collected by observation, interview, documentation, and questionnaires, while data analysis using chi square statistic.

Based on the analysis of data obtained count value $\mathrm{X}$ is greater than $\mathrm{X}$ tables, both at $1 \%$ significance level or at the level of significance of 5\%. Thus Ho is rejected, which means there is the influence of professionalism of teachers on learning achievement quran hadith students.

To determine the independent variables (Professional Teacher) and dependent variable (Achievement Qur'an Hadith Students) koefisienkontingensi then calculated using the formula (KK) or C, from the calculations, the price of $\mathrm{C}=0.514$ and compared $\mathrm{Cmax}=0,816$. When seen in the table there is a contingency coefficient values between 0.290 to 0.578 , it can be concluded that there is a fairly close relationship between the two variables.
\end{abstract}

Keywords: Professionalism, Teacher, Achievement, Learning

\begin{abstract}
ABSTRAK
Perkembangan dunia pendidikan ini semakin membutuhkan manajemen tata pengelolahan yang baik.Untuk menghadapi perkembangan dunia pendidikan tersebut di perlukan orang yang bener-bener ahli dalam bidangnya. Profesi pada hakikatnya adalah suatu pekerjaan yang memerlukan pengetahuan dan keterampilan yang berkualifikasi tinggi dalam melayani atau mengabdi kepentingan umum untuk mencapai kesejahteraan manusia terutama dalam bidang pendidikan. Penelitian ini secara umum bertujuan untuk menggali informasi tentang usaha untuk meningkatkan profesionalismeguru mata pelajaran Al-qur'an hadits di Madrasah Tsanawiyah GUPPI Kec. Sumberejo Kab.Tanggamus

Penelitian ini dilakukan terhadap 38 siswa Madrasah Tsanawiyah GUPPI Sumberejo (34\%) sebagai sampel dari jumlah populasi siswa sebanyak 117 yang terdiri dari kelas VII, VIII, dan kelas IX serta guru mata pelajaran Al-Qur'an Hadits. Data penelitian dikumpulkan dengan metode observasi, interview, dokumentasi, dan angket, sedangkan analisa datanya menggunakan metode statistik chi kuadrat.

Berdasarkan hasil analisis data didapatkan nilai $\mathrm{X}$ hitung lebih besar daripada $\mathrm{X}$ tabel, baik pada taraf signifikasi $1 \%$ maupun pada taraf signifikasi 5\%. Dengan demikian Ho ditolak, yang berarti terdapat pengaruh profesionalisme guru terhadap prestasi belajar al-qur'an hadits siswa.

Untuk mengetahui variabel bebas (Profesionalisme Guru) dengan variabel terikat (Prestasi Belajar AlQur'an Hadits Siswa) maka dihitung dengan rumus koefisienkontingensi (KK) atau C, dari hasil perhitungan diperoleh harga $\mathrm{C}=0,514$ dan dibandingkan $\mathrm{C}_{\text {maks }}=0,816$. Bila dilihat pada tabel koefisien kontingensi terdapat nilai antara 0,290-0,578, maka dapat disimpulkan bahwa ada hubungan yang cukup erat antara kedua variabel tersebut.
\end{abstract}

Kata Kunci :Profesionalisme, Guru, Prestasi, Belajar 


\section{A. PENDAhUluan}

Pendidikan merupakan usaha sadar dan terencana untuk mewujudkan suasana belajar dan proses pembelajaran agar peserta didik secara aktif mengembangkan potensi dirinya untuk memiliki kekuatan spiritual keagamaaan, pengendalian diri, kepribadian, kecerdasan, akhlak mulia, serta ketrampilan yang diperlukan dirinya, masyarakat, bangsa, dan Negara.

Sehubungan dengan hal tersebut seperti yang dikutip oleh Atmosudirdjo (1982: 60) bahwa :

Guru memiliki peran yang sangat besar dalam pendidikan, dipundaknya dibebani suatu tanggung jawab atas mutu pendidikan. Maka dari itu guru harus mengembangkan dirinya dengan ilmu pengetahuan dan keterampilanketerampilan yang di butuhkan dalam pembelajaran.

Bagi seseorang yang tidak mempunyai kompetensi profesional dalam mengajar maka akan mengakibatkan banyak kerugian. Hal ini sesuai dengan hadits Rasulullah SAW yang berbunyi:

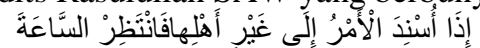

Artinya : "Jika urusan diserahkan bukan kepada ahlinya, maka tunggulah kehancuran itu." (Bukhari- 6015).

Ayat di atas, kaitannya dengan kompetensi guru yakni kompetensi merupakan suatu kemampuan yang harus dimiliki guru agar tugasnya sebagai pendidik dapat terlaksana dengan baik, sebab dalam mengelola proses belajar mengajar yang dilaksanakan guru yang tidak menguasai kompetensi guru, maka akan sulit untuk mencapai tujuan pembelajaran yang diinginkan dan apabila pendidikan di kendalikan oleh guru yang tidak mempunyai kompetensi sebagai pendidik maka impian untuk mencerdaskan anak bangsa sebagai tujuan utama pendidikan tidak akan pernah terwujud. Menurut Broke and Stone (2005) :

Kompetensi merupakan gambaran hakikat kualitatif dan perilaku guru dan tenaga kependidikan yang tampak sangat berarti.Dengan demikian, kompetensi merupakan perpaduan dari pengetahuan nilai dan sikap yang direfleksikan dalam kebiasaan bertindak dan berfikir.

Tidak semua kompetensi yang dimiliki seorang guru menunjukkan bahwa dia profesional, karena kompetensi profesional tidak hanya menunjukkan apa dan bagaimana melakukan pekerjaan, tetapi juga menguasai rasional yang dapat menjawab mengapa hal itu dilakukan berdasarkan konsep dan teori tertentu. Undang Undang No 14 tentang Guru dan Dosen (Yamin,2007:195) menyatakan:

Profesional adalah kegiatan atau pekerjaan yang dilakukan oleh seseorang dan menjadi sumber penghasilan kehidupan yang memerlukan keahlian, kemahiran atau kecakapan yang memenuhi standar mutu atau norma tertentu serta memerlukan pendidikan profesi.

Guru yang profesional dituntut harus memahami karakteristik setiap siswa, menerapkan metode yang sesuai dengan karakteristik siswa dan materi pelajaran, menguasai materi pelajaran yang akan disampaikan kepada siswa, melakukan evaluasi setelah selesai pembelajaran, serta dapat mengembangkan berbagai potensi yang dimiliki masing-masing siswa. Namun pada kenyataannya, sebagian guru memiliki kemampuan yang kurang untuk menentukan alat evaluasi, padahal hal tersebut sangat penting untuk membantu dan mengetahui sampai dimana pemahaman siswa ketika belajar.

Menurut Mulyasa (2012:20) menyatakan bahwa rendahnya profesionalisme guru disebabkan oleh:

1. guru tidak menekuni profesinya secara utuh;

2. belum adanya standar profesional guru sebagaimana tuntutan dinegara-negara maju;

3. adanya perguruan tinggi swasta yang mencetak guru asal jadi tanpa memperhitungkan outputnya kelak di dunia kerja;

4. kurangnya motivasi guru dalam meningkatkan kualitas diri karena guru tidak dituntut untuk melakukan penelitian

Hal ini dapat dijelaskan bahwa semakin tinggi kompetensi profesional guru maka semakin tinggi pula hasil yang dicapai oleh siswa. Hal ini dikarenakan bahwa keberhasilan pembelajaran di dalam kelas ditentukan oleh kompetensi profesionalisme guru. Keberhasilan pembelajaran di dalam kelas dapat ditandai dengan tingginya nilai ahir yang dicapai siswa, dalam hal ini yakni prestasi belajar siswa.

Prestasi belajar menurut Depdiknas (2007:895) merupakan hasil yang telah dicapai (dilakukan, dikerjakan, dan sebagainya).

Dalam dunia pendidikan (Suyati, Volume 2, Nomor 1, November : 2015) prestasi adalah suatu hal yang mutlak untuk dicapai. Hal itu dikarenakan tolak ukur sebuah proses belajar mengajar dapat dilihat dari prestasi yang dihasilkan siswa. Menurut Arifin, (1988: 3-4) prestasi mempunyai beberapa fungsi utama, antara lain prestasi belajar sebagai indikator kualitas dan kuantitas pengetahuan yang telah dikuasai siswa. menentukan keberhasilan suatu lembaga pendidikan. Fungsi lain prestasi belajar adalah sebagai indikator daya serap dan kecerdasan siswa (Atmoko \& Kholis, 2013). Nana Sudjana (2005:3) mendefinisikan prestasi adalah hasil belajar yang dicapai siswa dengan kriteria tertentu sehingga untuk mengetahui tingkat prestasi belajar maka perlu dilakukan evaluasi belajar.

Dari beberapa pengertian di atas dapat disimpulkan bahwa pengertian prestasi adalah yang telah dicapai dari usaha yang dilakukan sebelumnya dengan jalan keuletan bekerja dan 
dinampakkan dalam pengetahuan, sikap, dan keahlian.

Sementara pengertian belajar menurut Slameto, (2010:2) menyatakan:

Belajar ialah suatu proses usaha yang dilakukan seseorang untuk memperoleh suatu pemahaman tingkah laku yang baru secara keseluruhan, sebagai hasil pengalamannya sendiri dalam interaksi dengan lingkungannya.

Untuk mencapai prestasi belajar yang baik hendaknya siswa memperbanyak bertanya kepada guru tentang hal-hal yang belun di ketahuinya, sebagaimana di jelaskan dalam hadits di bawah ini :

العلم خاز ائن، ومفتا حها السؤال، فاسألو ا يرحمكما الله، فانه يؤجر فيه

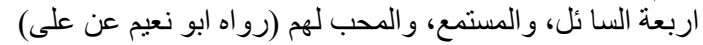

Artinya: $\quad$ Ilmu adalah gudang dan kuci pembuka gudang tersebut adalah pertanyaan/ permintaan. Maka kalian bertanyalah (pada guru / ulama) maka kalian akan di rahmat Allah, sesungguhnya ada empat orang yang akan pendapat / diberi pahala yaitu, orang yang bertanya, yang mengajarkan, yang mendengarkan, dan yang mencintai pada orang-orang tersebut. (H.R. Abu Nua'im dari Ali)

Dari beberapa pengertian di atas dapat disimpulkan bahwa pengertian prestasi belajar adalah sesuatu yang telah dicapai dari usaha yang telah dilakukan sebelumnya dengan jalan keuletan bekerja dan dinampakkan dalam pengetahuan, sikap, dan keahlian, yang menjadikan seseorang berubah tingkah lakunya sebagai bentuk dari hasil pengalaman dan interaksi dengan lingkungan.

Mudzakir dan Sutrisno (1997) mengemukakan faktor-faktor yang mempengaruhi prestasi belajar secara lebih rinci, yaitu:

a. Faktor internal (faktor dari dalam diri manusia). Faktor ini meliputi:

1) Faktor fisiologi (yang bersifat fisik) yang meliputi:

a) Karena sakit

b) Karena kurang sehat

c) Karena cacat tubuh

2) Faktor psikologi (faktor yang bersifat rohani)logi meliputi:

a) Intelegensi

b) Bakat

c) Minat

d) Motivasi

e) Faktor kesehatan mental

b. Faktor Eksternal

Faktor eksternal merupakan faktor yang berasal dari luar diri seseorang, faktor ini meliputi :

1) Lingkungan keluarga
Keluarga merupakan pusat pendidikan yang utama dan pertama. Yang termasuk faktor ini antara lain:

a) Perhatian orang tua

b) Keadaan ekonomi orang tua

c) Hubungan antara anggota keluarga dapat tercapai dengan baik pula.

2) Lingkungan sekolah

Yang dimaksud sekolah, antara lain :

a) Guru

b) Faktor alat

c) Kondisi gedung

3) Faktor mass media dan lingkungan sosial (masyarakat)

a) Faktor mass media meliputi ; bioskop, tv, surat kabar, majalah, buku-buku komik yang ada di sekeliling kita. Hal-hal itu yang akan menghambat belajar apabila terlalu banyak waktu yang dipergunakan, hingga lupa tugas belajar.

b) Lingkungan sosial

$>$ Teman bergaul

$>$ Lingkungan tetangga

> Aktivitas dalam masyarakat

Dengan demikian penulis dapat menyimpulkan bahwa profesi mengajar harus didasarkan pada adanya kompetensi dan kualifikasi tertentu bagi setiap orang yang hendak mengajar. Untuk itu seorang guru perlu memiliki kepribadian, menguasai bahan pelajaran dan menguasai caracara mengajar sebagai kompetensinya. Tanpa hal tersebut guru akan gagal dalam melaksanakan tugasnya.

Akan tetapi melihat realita yang ada, keberadaan guru professional sangat jauh dari apa yang dicitacitakan. Menjamurnya sekolah-sekolah yang rendah mutunya, memberikan suatu isyarat bahwa guru professional hanyalah sebuah wacana yang belum terealisasi secara merata. Hal ini menimbulkan suatu keprihatinan baik di kalangan akademis maupun orang awam.

Kenyataan tersebut menggugah kalangan akademi untuk membuat perumusan dalam meningkatkan kualifikasi guru, melalui pemberdayaan dan peningkatan profesionalisme guru dari pelatihan sampai dengan intruksi agar guru memilik ikualifikasi pendidikan minimal Strata 1 (S1). Yang menjadi permasalahan baru adalah sebagian besar guru memahami instruksi tersebut sebagai formalitas untuk memenuhi tuntutan kebutuhan yang sifatnya administratif. Sehingga kompetensi guru profesional dalam hal ini tidak menjadi prioritas utama.

Berdasarkan latar belakang itulah peneliti ingin melakukan research yang berkaitan dengan profesionalisme guru dan prestasi belajar siswa. Tempat atau lokasi penelitian adalah MTs GUPPI Kecamatan Sumberejo Tanggamus sebagai lembaga pendidikan yang memenuhi unsurunsur dalam variabel penelitian yaitu guru, 
siswa dan prestasi belajar. MTs GUPPI juga sudah terakreditasi serta memiliki guru-guru yang sudah lulus UKG.

\section{B. Tujuan Penelitian}

Penelitian ini secara umum bertujuan untuk menggali informasi tentang usaha untuk meningkatkan profesionalisme guru mata pelajaran Al-qur'an hadits di Madrasah Tsanawiyah GUPPI Kec. Sumberejo Kab.Tanggamusyaitu sebagai berikut:

1. Untuk mengetahui profesionalisme guru bidang studi Al-Qur'an Hadits di Madrasah Tsanawiyah GUPPI Kec. Sumberejo Kab.Tanggamus.

2. Untuk mengetahui Prestasi Belajar pada pelajaran Al-qur'an hadits siswa di Madrasah Tsanawiyah GUPPI Kec. Sumberejo Kab.Tanggamus

3. Untuk mengetahui hubungan Profesionalisme Guru Terhadap Prestasi Belajar Al-Qur'an Hadits Siswa kelas VII di Madrasah Tsanawiyah GUPPI Kec. Sumberejo Kab.Tanggamus.

\section{Hipotesis}

Berdasarkan kajian teori dan kerangka berfikir, maka dapat dirumuskan hipotesis penelitian sebagai berikut:

$\mathrm{Ha}$ : “terhadap hubungan antara kompetensi profesionalisme guru terhadap prestasi belajar

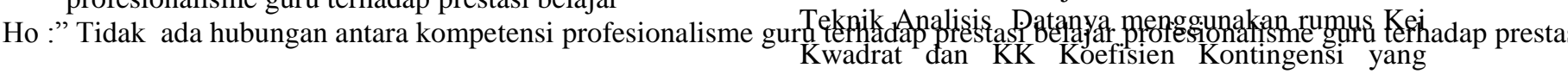

D. Metode Penelitian

Jenis penelitian yang dilakukan adalah penelitian deskriptif yang mengambil sampel dari suatu populasi secara langsung sebagai pengumpulan data yang pokok yaitu siswa yang belajar Di Madrasah Tsanawiyah GUPPI Sumberejo Tanggamus. Dalam penelitian ini, penulis menggunakan pendekatan kuantitatif karena penelitian ini merupakan suatu bentuk penelitian yang bersifat deskriptif kuantitatif. Dikatakan deskriptif kuantitatif karena penelitian ini bertujuan untuk mendiskripsikan hasil pengolahan data yang berupa angka. Lokasi penelitian ini dilakukan di Madrasah Tsanawiyah GUPPI Sumberejo kabupaten Tanggamus.

Data yang digunakan adalah data primer dan sekunder. Data primer merupakan data yang diperoleh langsung dari hasil wawancara dengan informan (Guru Al-Qur'an Hadits) hasil dari pertanyaan-pertanyaan yang diajukan dan berkaitan dengan masalah yang diteliti, dengan menggunakan wawancara dan kuisioner. Seedangkan data sekunder merupakan data yang diperoleh dari literatur-literatur kepustakaan seperti buku, serta sumber lainnya yang berkaitan dengan permasalahan penelitian dan analisis dokumentasi dari kondisi demografis dan sosiopolitik wilayah penelitian.

Instrumen Penelitian yang digunakan adalah angket, wawancara, pedoman pengamatan (observasi) dan dokumentasi.

Angket disebarkan kepada siswa kelas VII sebanyak 38 orang dengan mengajukan beberapa pertanyaan, dengan harapan mereka dapat menjawab angket tersebut dengan benar dan jujur untuk menentukan realita sebagaimana penulis harapkan. Angket dalam penelitian ini penulis gunakan sebagai metode pokok ditujukan kepada guru dan siswa digunakan untuk mengetahui seberapa besar pengaruh kompetensi profesional guru terhadap prestasi belajar siswa.

Interview penulis gunakan pada guru Al-Qur'an Hadits serta siswa untuk mengetahui tentang kompetensi profesional guru seperti dalam merencanakan sistem pembelajaran, pelaksanaan pembelajaran dan evaluasi hasil pembelajaran pada siswa serta pengaruhnya terhadap prestasi belajar siswa. Sedangkan observasi digunakan untukmengetahui prestasi belajar Al-Qur'an Hadits siswa kelas VII A dan VII B, meliputi hasil Prestasi Belajar semester ganjil dan Kriteria Ketuntasan Minimum.

Teknik pengumpulan data yang lain adalah dokumentasi. Ini digunakan untuk mencatat dokumentasi tentang keadaan tenaga pendidik dan kependidikan, keadaansiswa, dan keadaan sarana dan prasarana yang ada di Madrasah Tsanawiyah GUPPI Kec. Sumberejo. bertujuan untuk mengetahui hubungan antara profesionalisme guru dan prestasi belajar siswa, yang diformulasikan sebagai berikut:

$$
\chi^{2}=\Sigma \frac{(f o-f t)^{2}}{f t}
$$

Keterangan:

$X^{2} \quad$ : Nilai Chi-kuadrat

fo : frekuensi yang di peroleh

ft : frekuensi yang di harapkan

Rumus koefisien kontingensi (KK) dilambangkan dengan huruf $\mathrm{C}$ :

$C=\sqrt{\frac{x^{2}}{x^{2}+N}}$

Dimana :

$\mathrm{KK}=$ Koefisien Kontingensi

$\chi^{2}=$ Chi Kuadrat

$\mathrm{N} \quad=$ Jumlah sample penelitian

Hasil perhitungan data baik dari setiap variabel diklasifikasikan kedalam tiga kategori yaitu baik, cukup, dan kurang. 


\section{E. Pembahasan}

Madrasah Tsanawiyah GUPPI Sumberejo Kab Tanggamus di prakarsai atau dirintis oleh bapak Kyai Misbahudin. Adapun nama MTs GUPPI Sumberejo tersebut pada awal mulanya adalah MTs Nurul Umah di bawah naungan Yayasan PEMNU Talang Padang yang berdiri pada tahun 1980. Pada tahun 1990 MTs GUPPI Nurul Umah melepaskan diri dari Yayasan PEMNU talang padang yang beralih dan berada dalam naungan Yayasan GUPPI Sumberejo.

Keberadaan MTs GUPPI Sumberejo Kecamatan Sumberejo Kabupaten Tanggamus mengalami perkembangan prestasi dan mendapat apresiasi yang baik dari masyarakat maupun dari Departemen Pendidikan Agama. Dengan perkembangan yang baik , maka pada tahun 2006, MTs GUPPI Sumberejo yang dari status terdaftar menjadi terakreditasi.

Visi Madrasah Tsanawiyah GUPPI Sumberejo adalah Mewujudkan MTs GUPPI Sumberejo sebagai area pendidikan yang kondusif dan saran akomunikasi warga madrasah yang harmonis berdasarkan iptek dan imtaq. Sedangkan Misinya adalah:

1) Memperjuangkan mutu pendidikan

2) Mengembangkan daya kreativitas yang inovatif

3) Menggalang silaturrahmi yang harmonis

4) Memperjuangkan kesejahteraan

Proses belajar mengajar merupakan inti dari proses pendidikan secara keseluruhan dengan guru pemegang peranan utama, karena mereka adalah faktor yang menentukan bagi keberhasilan pengajaran. Tanpa guru proses belajar mengajar tidak akan langsung, dengan demikian tujuan pendidikan akan tercapai. Keadaan Guru (tenaga pendidikan) Madrasah Tsanawiyah GUPPI Sumberejo Kecamatan Sumberejo Kabupaten Tanggamus pada Tahun Pelajaran 2013/2014 berjumlah 18 orang guru tidak tetap (Honorer). Sedangkan jumlah siswa MTs GUPPI Sumberejo Kecamatan Sumberejo pada tahun pelajaran 2013/2014 ini seluruhnya berjumlah 117 orang, dengan perincian sebagai berikut:

Tabel 7

Keadaan Kelas dan siswa MTs GUPPI Tahun pelajaran 2013/2014

\begin{tabular}{|c|c|c|c|c|c|}
\hline \multirow{2}{*}{ No } & \multirow{2}{*}{ Kelas } & Jumlah & \multicolumn{2}{|c|}{ Siswa } & \multirow{2}{*}{ Jumlah } \\
\cline { 3 - 6 } & & Kelas & perempuan & $\begin{array}{c}\text { Laki- } \\
\text { laki }\end{array}$ & \\
\hline 1 & VII & 2 & 16 & 22 & 38 \\
\hline 2 & VIII & 2 & 26 & 25 & 53 \\
\hline 3 & IX & 1 & 14 & 12 & 26 \\
\hline Jumlah
\end{tabular}

Sumber : Dokumen MTs GUPPI

\section{Profesionalisme Guru}

Untuk mengetahui secara umum data tentang profesionalisme guru, penulis mengadakan penelitian melalui metode angket tidak langsung yang ditujukan kepada siswa yang menjadi sampel penelitian. Untuk memperoleh skor dalam angket berdasarkan jawaban yang diperoleh dari responden, setiap item mempunyai skor yaitu:

- Alternatif jawaban a diberi skor $3=$ baik

- Alternatif jawaban b diberi skor $2=$ cukup

- Alternatif jawaban c diberi skor $1=$ cukup Adapun hasil data tersebut selengkapnya dapat penulis sajikan dalam tabel berikut ini :

Tabel 9. Hasil Angket

Tentang Profesionalisme Guru MTs GUPPI Sumberejo

\begin{tabular}{|c|c|c|c|c|c|c|c|c|c|c|c|}
\hline $\begin{array}{c}\text { No } \\
\text { Sampel }\end{array}$ & $\mathbf{1}$ & $\mathbf{2}$ & $\mathbf{3}$ & $\mathbf{4}$ & $\mathbf{5}$ & $\mathbf{6}$ & $\mathbf{7}$ & $\mathbf{8}$ & $\mathbf{9}$ & $\mathbf{1 0}$ & \\
\hline 1 & 3 & 3 & 3 & 3 & 2 & 2 & 3 & 3 & 2 & 2 & 26 \\
\hline 2 & 3 & 3 & 3 & 3 & 3 & 3 & 3 & 3 & 3 & 3 & 30 \\
\hline 3 & 3 & 3 & 3 & 3 & 3 & 3 & 2 & 3 & 3 & 3 & 29 \\
\hline 4 & 2 & 2 & 3 & 3 & 3 & 2 & 2 & 3 & 3 & 3 & 26 \\
\hline 5 & 3 & 3 & 2 & 3 & 2 & 3 & 3 & 3 & 3 & 3 & 28 \\
\hline 6 & 2 & 2 & 2 & 2 & 3 & 1 & 3 & 2 & 2 & 1 & 20 \\
\hline 7 & 3 & 3 & 3 & 3 & 3 & 2 & 3 & 3 & 2 & 3 & 28 \\
\hline 8 & 3 & 2 & 3 & 3 & 2 & 3 & 3 & 3 & 3 & 2 & 27 \\
\hline 9 & 3 & 3 & 3 & 2 & 3 & 3 & 3 & 3 & 3 & 3 & 29 \\
\hline 10 & 3 & 3 & 2 & 3 & 1 & 2 & 3 & 3 & 1 & 1 & 22 \\
\hline 11 & 3 & 2 & 2 & 2 & 1 & 1 & 2 & 3 & 2 & 1 & 19 \\
\hline 12 & 2 & 3 & 3 & 3 & 2 & 3 & 2 & 3 & 2 & 3 & 26 \\
\hline 13 & 3 & 2 & 3 & 3 & 3 & 2 & 3 & 2 & 2 & 2 & 25 \\
\hline 14 & 3 & 2 & 3 & 3 & 3 & 3 & 3 & 3 & 3 & 3 & 29 \\
\hline 15 & 3 & 3 & 2 & 3 & 3 & 2 & 2 & 3 & 2 & 3 & 26 \\
\hline 16 & 3 & 3 & 2 & 3 & 2 & 3 & 3 & 2 & 3 & 3 & 27 \\
\hline 17 & 3 & 3 & 2 & 3 & 3 & 2 & 2 & 3 & 3 & 3 & 27 \\
\hline 18 & 3 & 3 & 3 & 3 & 3 & 3 & 3 & 3 & 3 & 3 & 30 \\
\hline 19 & 3 & 2 & 2 & 2 & 2 & 2 & 3 & 2 & 2 & 1 & 21 \\
\hline 20 & 3 & 2 & 3 & 3 & 3 & 3 & 3 & 3 & 3 & 3 & 29 \\
\hline 21 & 3 & 2 & 3 & 3 & 2 & 2 & 3 & 2 & 3 & 2 & 25 \\
\hline 22 & 3 & 3 & 3 & 3 & 2 & 3 & 3 & 3 & 3 & 2 & 28 \\
\hline 23 & 2 & 3 & 3 & 3 & 3 & 2 & 3 & 3 & 3 & 3 & 28 \\
\hline 24 & 3 & 3 & 3 & 2 & 2 & 2 & 3 & 3 & 3 & 2 & 26 \\
\hline 25 & 2 & 3 & 3 & 3 & 2 & 2 & 3 & 3 & 2 & 2 & 25 \\
\hline 26 & 2 & 2 & 2 & 2 & 2 & 3 & 2 & 2 & 3 & 2 & 22 \\
\hline 27 & 2 & 3 & 3 & 3 & 2 & 3 & 2 & 3 & 3 & 3 & 27 \\
\hline 28 & 3 & 2 & 2 & 2 & 2 & 3 & 3 & 3 & 2 & 2 & 24 \\
\hline 29 & 3 & 3 & 3 & 2 & 3 & 3 & 2 & 2 & 3 & 2 & 26 \\
\hline 30 & 2 & 3 & 2 & 3 & 3 & 2 & 2 & 2 & 2 & 2 & 23 \\
\hline 31 & 3 & 3 & 2 & 3 & 2 & 2 & 2 & 3 & 3 & 3 & 26 \\
\hline 32 & 3 & 2 & 2 & 2 & 1 & 2 & 3 & 2 & 2 & 1 & 20 \\
\hline & & & & & & & & \\
\hline
\end{tabular}




\begin{tabular}{|c|c|c|c|c|c|c|c|c|c|c|c|}
\hline \multirow{2}{*}{$\begin{array}{c}\text { No } \\
\text { Sampel }\end{array}$} & \multicolumn{10}{|c|}{ Skor Item Angket } & f \\
\hline 33 & 3 & $\mathbf{2}$ & $\mathbf{3}$ & $\mathbf{4}$ & $\mathbf{5}$ & $\mathbf{6}$ & $\mathbf{7}$ & $\mathbf{8}$ & $\mathbf{9}$ & $\mathbf{1 0}$ & \\
\hline 34 & 2 & 3 & 2 & 3 & 3 & 3 & 2 & 3 & 2 & 3 & 27 \\
\hline 35 & 3 & 2 & 2 & 3 & 3 & 2 & 2 & 2 & 2 & 3 & 24 \\
\hline 36 & 2 & 3 & 2 & 3 & 2 & 2 & 1 & 2 & 1 & 2 & 20 \\
\hline 37 & 3 & 3 & 3 & 2 & 3 & 3 & 2 & 2 & 3 & 3 & 27 \\
\hline 38 & 3 & 3 & 3 & 3 & 2 & 3 & 3 & 3 & 3 & 3 & 29 \\
\hline
\end{tabular}

Dari hasil angket tersebut, skor tertinggi adalah 30 dan skor terendah adalah 10 dengan jumlah frekuensi adalah 38. Untuk mengetahui interval kelasnya digunakan rumus sebagai berikut :

Interval $=\frac{\text { nilai tertinggi }- \text { nilai terendah }+1}{\text { jumlah } \text { kategori }}$

Selanjutnya penulis mengklasifikasikan profesionalisme guru dengan kategori yaitu baik, cukup, kurang. Maka diperoleh interval kelasnya yaitu: $\frac{30-10+1}{3}=7$

Jumlah interval untuk variabel bebas penelitian ini (profesionalisme guru) adalah 7 (tujuh). Setelah diketahui nilai intervalnya maka data dari interval di atas dimasukkan dalam tabel distribusi frekuensi sebagai berikut :

Tabel 10. Distribusi Frekuensi Hasil Angket Tentang Profesionalisme Guru

\begin{tabular}{|c|c|c|c|c|}
\hline No & $\begin{array}{c}\text { Interval } \\
\text { Kelas }\end{array}$ & Frekuensi & Kategori & \% \\
\hline 1 & $26-30$ & 7 & Baik & $18,4 \%$ \\
2 & $22-25$ & 24 & Cukup & $63,2 \%$ \\
3 & $18-21$ & 7 & Kurang & $18,4 \%$ \\
\hline \multicolumn{2}{r|}{ Jumlah } & $\mathbf{3 8}$ & & $\mathbf{1 0 0 \%}$ \\
\hline
\end{tabular}

Berdasarkan tabel distribusi frekuensi di atas dapat diketahui bahwa 38 siswa yang menjadi sampel penelitian antara 26-30 sebanyak 7 orang siswa yang menjawab baik 18,4\%, dan antara 22-25 sebanyak 24 orang siswa yang menjawab cukup $63,2 \%$, serta antara 18-21 sebanyak 7 orangsiswa yang menjawab kurang $18,4 \%$. Data data tersebut maka dapat dipahami Pengaruh Profesionalisme Guru dapat dikatakan cukup.

Kemudian untuk mengetahui secara umum data untuk Prestasi Belajar AL-Qur'an Hadits, penulis mengambil data nilai semester dari buku legger masing-masing kelas yang ada di Madrasah Tsanawiyah GUPPI Sumberejo. Adapun hasil data tersebut yang penulis dapat dari buku legger siswa selengkapnya dapat penulis sajikan dalam tabel berikut :

Tabel 11. Data Nilai Semester Ganjil Mata Pelajaran Al-Qur'an Hadits Tahun Pelajaran 2013/2014

\begin{tabular}{|l|l|l|l|}
\hline No & Nama Siswa & Kelas & Nilai \\
\hline 1 & Ari Muhtar & VII A & 75 \\
\hline 2 & Arif Azhari & VII A & 80 \\
\hline 3 & Arum Karisma & VII A & 79 \\
\hline 4 & Dian Ayu Lertari & VII A & 75 \\
\hline 5 & Edi Ferdian & VII A & 78 \\
\hline 6 & Irma Apriyanti & VII A & 62 \\
\hline 7 & Juriayah & VII A & 78 \\
\hline 8 & Khoirul Munawar & VII A & 77 \\
\hline 9 & Meli Novita Sari & VII A & 79 \\
\hline 10 & Maulana Rauf Hakiki & VII A & 67 \\
\hline 11 & Nasifatul Fitrah & VII A & 60 \\
\hline 12 & Novita Lutfayani & VII A & 75 \\
\hline 13 & Nur Wita Tarna Sari & VII A & 70 \\
\hline 14 & Rahmad Dwi Anggoro & VII A & 79 \\
\hline 15 & Slamet & VII A & 75 \\
\hline 16 & Tegar Irawan & VII A & 77 \\
\hline 17 & Umi Latifah & VII A & 77 \\
\hline 18 & Ade Irfan & VII A & 80 \\
\hline 19 & Beni Priyadi & VII A & 64 \\
\hline 20 & Eka Wulandari & VII B & 79 \\
\hline 21 & Khairul Anam & VII B & 70 \\
\hline 22 & Ike Putri Susanti & VII B & 78 \\
\hline 23 & Jupri & VII B & 78 \\
\hline 24 & Kiki Tria Ningsih & VII B & 75 \\
\hline 25 & Khoirudatin Masroah & VII B & 79 \\
\hline 26 & M. Julianto & VII B & 67 \\
\hline 27 & M. Agus Kurniawan & VII B & 77 \\
\hline 28 & M. Fajar Ansori & VII B & 69 \\
\hline 29 & M. Ansori & VII B & 75 \\
\hline 30 & Miftahul Jannah & VII B & 68 \\
\hline 31 & Nurul Istikomah & VII B & 75 \\
\hline 32 & Nguyun Hasanah & VII B & 62 \\
\hline 33 & Rajib Hidayatulloh & VII B & 77 \\
\hline 34 & Rini Yunita Sari B B & 78 \\
\hline 35 & Ridho Rahmadi & 69 \\
\hline 36 & Rijal Maryanda & 62 \\
\hline 37 & Uswatun Hasanah & 77 \\
\hline 38 & Yulianti & & \\
\hline & & VII & 79 \\
\hline
\end{tabular}

Dari hasil angket tersebut, menyatakan bahwa nilai tertinggi adalah 80 dan nilai terendah adalah 60 . Untuk mengetahui interval kelasnya digunakan rumus sebagai berikut :

Interval $=\frac{\text { nilai tertinggi }- \text { nilai terendah }+1}{\text { jumlah } \text { kategori }}$

Selanjutnya penulis mengklasifikasikan Prestasi Belajar Al-Qur'an Hadits siswa dengan 3 kategori yaitu baik, cukup, kurang.

Dari rumus sebelumnya, maka diperoleh interval kelasnya yaitu: $\frac{80-60+1}{3}=7$ 
Jumlah interval untuk variabel bebas penelitian ini (Prestasi Belajar Al-Qur'an Hadits) adalah 7 (tujuh) setelah diketahui nilai intervalnya maka data dari interval di atas dimasukkan dalam tabel distribusi frekuensi sebagai berikut :

Tabel 12. Distribusi frekuensi

Tentang Prestasi Belajar Al-Qur'an Hadits Tahun Pelajaran 2013/2014

\begin{tabular}{|c|c|c|c|c|}
\hline No & $\begin{array}{c}\text { Interval } \\
\text { Kelas }\end{array}$ & $\mathbf{F}$ & Kategori & \% \\
\hline 1 & $74-80$ & 25 & Baik & $65,8 \%$ \\
2 & $67-73$ & 8 & Cukup & $21,1 \%$ \\
3 & $60-66$ & 5 & Kurang & $13,2 \%$ \\
\hline \multicolumn{2}{|r|}{ Jumlah } & $\mathbf{3 8}$ & & $\mathbf{1 0 0 \%}$ \\
\hline
\end{tabular}

Berdasarkan tabel distribusi frekuensi di atas dapat diketahui bahwa 38 siswa yang menjadi sampel penelitian yang tergolong prestasinya baik ada 25 siswa atau $65,8 \%$, prestasinya cukup ada 8 siswa atau $21,1 \%$, dan prestasinya kurang ada 5 siswa atau $13,2 \%$. Dengan demikian dapat dipahami bahwaPrestasi Belajar siswa pada mata pelajaran Al-Qur'an Hadits Di Madrasah Tsanawiyah GUPPI Sumberejo Tahun Pelajaran 2013/2014 dikatakan baik.

\section{Hubungan Profesionalisme Guru dan Prestasi Belajar}

Untuk mengetahui tingkat hubungan antar variabel penelitian dapat diketahui dengan chi kuadrat dan dan teknik analisis srosstab sebagai berikut:

Tabel 13

Distribusi frekuensi

Hubungan Profesionalisme Guru

TerhadapPrestasi Belajar Siswa

\begin{tabular}{|l|c|c|c|c|}
\hline $\begin{array}{c}\text { Pengaruh } \\
\text { Profesiona } \\
\text { lisne guru } \\
\begin{array}{c}\text { Prestasi } \\
\text { Belajar } \\
\text { siswa }\end{array}\end{array}$ & Baik & Cukup & Kurang & N \\
\hline $\begin{array}{c}\text { Baik } \\
\text { Cukup }\end{array}$ & 21 & 2 & 1 & 24 \\
Kurang & 2 & 3 & 2 & 7 \\
\hline NJumlah & 25 & 8 & 5 & 38 \\
\hline
\end{tabular}

Menurut frekuensi yang diperoleh ( $\left.\mathrm{f}_{o}\right)$ dari tabel di atas, sehingga dapat diperloleh nilai yang diharapkan $(f t)$ dari sampel dengan rumus sebagai berikut :

$$
\chi^{2}=\Sigma \frac{(f o-f t)^{2}}{f t} 1
$$

Tabel 14. Tabel perhitungan Chi kuadrat Hubungan Profesionalisme Guru dengan Prestasi Belajar Siswa

\begin{tabular}{|c|c|c|c|c|c|}
\hline No & Fe, & $F t$ & $(f e-f t)$ & $(f e-f t)^{2}$ & $\frac{(f o-f t)}{f t}$ \\
\hline 1 & 2 & $\frac{7 \times 25}{38}-4,61$ & $-2,61$ & 6,79 & 1,47 \\
\hline 2 & 3 & $\frac{7 \times 8}{38}=1.47$ & 1,53 & 2,33 & 1,58 \\
\hline 3 & 2 & $\frac{7 \times 5}{38}-0,92$ & 1,08 & 1,16 & 1,26 \\
\hline 4 & 21 & $\frac{24 \times 25}{38}-1579$ & 5,21 & 27 & 1,72 \\
\hline 5 & 2 & $\frac{24 \times 8}{38}=5,05$ & $-3,05$ & 9,32 & 1.84 \\
\hline 6 & 1 & $\frac{24 \times 5}{38}=3,16$ & $-2,16$ & 4,66 & 1.47 \\
\hline 7 & 2 & $\frac{7 \times 25}{38}-4,61$ & $-2,61$ & 6.79 & 1,47 \\
\hline 8 & 3 & $\frac{7 \times 8}{38}-1.47$ & 1,53 & 2,33 & 1.58 \\
\hline 9 & 2 & $\frac{7 \times 5}{38}-0,92$ & 1.08 & 1,16 & 1,26 \\
\hline Jup & h.38 & & & & 13,68 \\
\hline
\end{tabular}

Berdasarkan tabel di atas, maka dapat diketahui bahwa harga Chi kuadrat $\left(\chi^{2}\right)$ adalah sebesar 13,68, selanjutnya untuk mengetahui ada atau tidaknya hubungan Profesionalisme guru dengan Prestasi Belajar Al Qur'an Hadits Siswa harus diuji dengan nilai chi kuadrat dengan tabel kriteria pengujian dengan derajat kebebasan (d.b) $=4$, diperoleh dari perkalian jumlah kolom -1 dengan jumlah baris -1 atau $(3-1)(3-1)=4$. Dimana harga chi kuadrat tabel d.b $=4$, untuk taraf signifikasi $5 \%$ $=9,488$ dan untuk taraf sifnifikasi $1 \%=13,227$ dengan demikian harga Chi kuadrat $\left(\chi^{2}\right)$ hitung lebih besar dari pada harga Chi kuadrat $\left(\chi^{2}\right)$ tabel baik pada taraf signifikansi $1 \%$ maupun pada taraf sifnifikasi $5 \%$ atau 9,488<13,68>13,227.

Selanjutnya berdasarkan hasil perhitungan di atas, untuk mengetahui seberapa besar hubungan variabel bebas (Profesinalisme guru) dengan variabel terikat (Prestasi Belajar Al Qur'an Hadits) dapat digunakan Koefisien Kontingensi (KK) yang sering dilambangkan dengan $\mathrm{C}$ dengan rumus sebagai berikut :

$$
\begin{aligned}
C & =\sqrt{\frac{x^{2}}{x^{2}+N}} \\
& =\sqrt{\frac{13,68}{13,68+38}}
\end{aligned}
$$




$$
\begin{aligned}
& =\sqrt{\frac{13,68}{51,68}} \\
& =\sqrt{0,2647} \\
& =0,514
\end{aligned}
$$

Agar harga $\mathrm{C}$ yang diperoleh dapat dipakai untuk menilai derajat asosiasi antara faktor, maka harga $\mathrm{C}$ ini perlu dibandingkan dengan koofisien kontingensi maksimum, yang bisa terjadi. Harga $\mathrm{C}$ maksimum ini dihitung dengan rumus $=$

$$
\mathrm{C}_{\text {maks }}=\sqrt{\frac{m-1}{m}}
$$

$\mathrm{m}$ disini adalah harga minimum antara banyak baris dan kolom. Dalam perhitungan di atas, daftar kontingensi terdiri atas 3 baris dan 3 kolom, sehingga $=$

$$
\begin{aligned}
\mathrm{C}_{\text {maks }} & =\sqrt{\frac{3-1}{3}} \\
& =\sqrt{\frac{2}{3}} \\
& =\sqrt{0,666} \\
& =0,816
\end{aligned}
$$

Makin dekat harga $\mathrm{C}$ kepada $\mathrm{C}$ maks makin besar derajat asosiasinya. Dengan kata lain faktor yang satu makin berpengaruh dengan faktor yang lain, dari perhitungan di atas diperoleh harga $\mathrm{C}=0,514$ dengan $\mathrm{C}$ maks $=0,816$. Kemudian dilihat pada koefisien KK maksimal yaitu ada hubungan yang cukup erat. Jadi ada hubungan yang cukup erat antara Profesionalisme Guru terhadap Prestasi Belajar Al Qur'an Hadits. Dengan demikian hipotesis alternative Ha diterima dan hipotesis nol (Ho) ditolak.

\section{F. Penutup}

Berdasarkan penelitian yang penulis lakukan, diketahui bahwa guru Madrasah Tsanawiyah GUPPI Sumberejo khususnya guru mata pelajaran Al-qur'an Hadits telah melakukan tugasnya sebagai guru yang professional yakni dalam proses pembelajaran guru telah melaksanakan perencanaan pembelajaran sesuai dengan RPP dan silabus, melaksanakan system pembelajaran, mengevaluasi hasil pembelajaran, serta dalam mengembangkan sistem pembelajaran.

Hasilnya dapat di ketahui pada nilai semester siswa yang baik. Berdasarkan tabel distribusi frekuensi dapat diketahui bahwa 38 siswa yang menjadi sampel penelitian yang tergolong prestasinya baik ada 25 siswa, prestasinya cukup ada 8 siswa, dan prestasinya kurang ada 5 siswa. Dengan demikian dapat dipahami bahwa Pengaruh profesionalisme guru mempunyai pengaruh terhadap prestasi belajar Al-Qur'an Hadits siswa di
Madrasah Tsanawiyah GUPPISumberejo Kecamatan Sumberejo Kabupaten Tanggamus. Berdasarkan hasil pengujian diatas ternyata Chi kuadrat $\left(\chi^{2}\right)$ hitung lebih besar dari pada Chi kuadrat $\left(\chi^{2}\right)$ tabel, baik pada taraf signifikasi $1 \%$ maupun maupun pada taraf signifikansi $5 \%$. Dengan demikian hipotesis yang penulis ajukan dapat diterima yaitu yang berarti ada pengaruh profesionalisme guru terhadap Prestasi belajar $\mathrm{Al}$ Qur'an Hadits.Kemudian hipotesis nihil (Ho) ditolak.

Untuk mengetahui keterkaitan faktor yang satu dengan faktor yang lain yaitu variabel bebas (Profesionalisme guru) dengan variabel terikat (Prestasi belajar Al Qur'an Hadits ) maka dihitung dengan rumus koefisien kontingensi $(\mathrm{KK})$ atau $\mathrm{C}$, dari hasil perhitungan diperoleh harga $\mathrm{C}=0,514$ dan dibandingkan $C_{\text {maks }}=0,816$. Bila dilihat pada tabel koefisien kontingensi terdapat diantara 0,2900,578 itu ada keterkaitan yang cukup erat antara pengaruh Profesionalisme Guru Terhadap Prestasi Belajar Al Qur'an Hadits.

\section{Daftar Pustaka}

Atmosudirjo, Prajudi Tahun 1982. Tentang Peran Guru

Beny Tri Atmoko \& Nur Kholis. 2013. Pengaruh Prestasi Belajar Mata Pelajaran Adaptif Dan Pola Asuh Orang Tua Terhadap Prestasi Belajar Mata Pelajaran Produktif Siswa Jurusan Titl Smk Negeri 1 Magelang. Jurnal Skripsi. Program Studi Pendidikan Teknik Mekatronika. Universitas Negeri Yogyakarta.

Depdiknas. (2007). Kamus Besar Bahasa Indonesia. Jakarta: Balai Pustaka.

M. Bukhori, M.Ed.,Teknik-Teknik Evaluasi Dalam Pendidikan, (Bandung : Jemmars,2009), Edisi Revisi.

Maisah dan Yamin. 2010. Standarisasi Kinerja Guru. Jakarta : Gaung Persada Press.

Mulyasa. 2013. Uji Kompetensi dan Penilaian Kinerja Guru. Bandung: Remaja Rosdakarya.

Mursid \& Maryadi. 2012. Perbedaan Minat Dan Prestasi Belajar Siswa Pada Mata Diklat Mengoperasikan Sistem Pengendali Elektronik Dengan Menggunakan Software Tutorial Plc Siswa Kelas Xi Smk Negeri 2 Pengasih. Jurnal Skripsi. Program Studi Pendidikan Teknik Mekatronika Fakultas Teknik. Universitas Negeri Yogyakarta

Nana Sudjana. (2005). Penilaian Hasil Proses Belajar Mengajar Bandung:

Remaja Rosdakarya. 
Slameto.,Drs.,Belajar dan Factor-Faktor Yang Mempengaruhi, (Jakarta . Rineka Cipta, 2010) cet. Ke-14.

Sudjana, Cara Siswa Belajar Aktiv dalam Proses Belajar Mengajar, (Bandung : Sinar Baru Algensindo, 1989).

Suyati. 2015. Peningkatan Prestasi Belajar Siswa Dalam Mata Pelajaran Matematika Operasi Hitung Perkalian Dengan Metode Bermain Kartu. Jurnal Paradigma. Volume 2, Nomor 1, November: ISSN 2406-9787 